\title{
TEORIA CRÍTICA, SOCIEDADE E EDUCAÇÃO: REFLEXÕES SOBRE AS TENSÕES DA ERA TECNOLÓGICA NA INFÂNCIA
}

Danielle Regina do Amaral Cardoso*

Resumo: Esse artigo consiste em uma reflexão sobre as tensões provocadas pela forte presença das tecnologias e o crescente progresso técnico na formação das crianças. Em meio a uma infância tecnológica, há uma melancolia em função da priorização do apego às máquinas em detrimento das relações humanas. Trata-se de uma análise proveniente de uma tese de doutorado embasada na Teoria Crítica, com a contribuição de autores afins.

Palavras-chaves: Infância; Tecnologia; Formação; Sociedade.

Resumen: Este artículo consiste en una reflexión sobre las tensiones provocadas por la fuerte presencia de las tecnologías y el creciente progreso técnico en la formación de los niños. En medio de una infancia tecnológica, hay una melancolía en función de la priorización del apego a las máquinas en detrimento de las relaciones humanas. Se trata de un análisis proveniente de una tesis de doctorado basada en la Teoría Crítica, con la contribución de autores afines.

Palabras claves: Infancia; Tecnología; Formación; Sociedad.

Dia-a-dia nega-se às crianças o direito de ser criança.

Os fatos, que zombam desse direito, ostentam seus ensinamentos na vida cotidiana. $\mathrm{O}$ mundo trata os meninos ricos como se fossem dinheiro, para que se acostumem a atuar como o dinheiro atua. O mundo trata os meninos pobres como se fossem lixo, para que se transformem em lixo. E os do meio, os que não são ricos, nem pobres, conserva-os atados à mesa do televisor, para que aceitem desde cedo como destino, a vida prisioneira.

Muita magia e muita sorte têm as crianças que conseguem ser crianças.

Eduardo Galeano (1999), $A$ escola do mundo às avessas.

\footnotetext{
* Doutora em Educação pelo Programa de PósGraduação em Educação Escolar da Faculdade de Ciências e Letras de Araraquara - FCLar/UNESP.
}

CARDOSO, Danielle Regina do Amaral. Teoria Crítica, Sociedade e Educação: reflexões sobre as tensões da era tecnológica na infância. Revista Sul-Americana de Filosofia e Educação. Número 29: nov./2017-abr./ 2018, p. 5-18. DOI: https://doi.org/10.26512/resafe.v0i29.21004 
A sociedade atual encontra-se marcada por paradoxos que, ao mesmo tempo em que promove certa "liberdade" aos indivíduos, acaba por aprisioná-los cada vez mais, provocando uma claustrofobia social. Enquanto a forte presença das tecnologias dissemina imagens e informações constantes, o crescente progresso técnico e o avanço do conhecimento científico potencializam a racionalidade instrumental em detrimento da dimensão humana. $\mathrm{Na}$ Dialética do Esclarecimento, Adorno e Horkheimer (1985) enfatizavam que "a maldição do progresso irrefreável é a irrefreável maldição" e, por meio de uma reflexão entre mito e esclarecimento apontavam para o aprisionamento do homem, que mediante seu anseio por poder e conhecimento, se mantinha preso nas amarras de sua própria razão. Para eles "o preço que os homens pagam pelo aumento de seu poder é a alienação daquilo sobre o que exercem o poder." (ADORNO e HORKHEIMER, 1985, p. 21).

Mas, para contextualizar uma reflexão acerca dos desdobramentos do progresso técnico, é preciso levar em consideração, primeiramente, que a concepção de sociedade vem se modificando em função das necessidades sociais do indivíduo, que carece de propagandear-se para sentir-se socialmente aceito. Nessa perspectiva, as contribuições de pensadores que teceram considerações acerca do irrefreável avanço da microeletrônica e da invasão de imagens em meio às relações sociais, nos permitem reflexões sobre diferentes contextos que já apontavam para um predomínio da razão instrumental e uma crise nos aspectos humanos, culturais. Tais contribuições proporcionaram um olhar crítico para os materiais infantis coletados em uma pesquisa cujo foco era a contradição que marcava severamente uma aproximação estreita entre as crianças $e$ as telas, em contraposição ao distanciamento das relações efetivamente humanas.

Em 1967, com a publicação da Sociedade do Espetáculo, Debord buscou uma caracterização da sociedade mediante os fetiches do capital que tratou de espetacularizar a realidade, transformando tudo em um grande espetáculo social. Para esse filósofo, a crítica da sociedade consistia em demonstrar que, de fato, todas as relações no mundo capitalista eram permeadas por imagens e difundidas pelos meios eletrônicos, midiáticos, o que as tornavam espetaculares.

Ao anunciar que "o primeiro mérito de uma teoria crítica exata é fazer parecerem ridículas, de imediato, todas as demais." (DEBORD, 1997, p. 151), o autor rompeu as barreiras epistemológicas e paradigmáticas até então existentes para fazer uma análise crítica da sociedade do consumo e dos meios de comunicação. Debord (1997) se ateve à análise da tirania das imagens e ao caráter espetacular de tudo que a mercadoria e o capital passaram a dominar, afastando os homens entre si e aproximando-os das produções materiais.

Adorno falou sobre esse amor às máquinas que, de certa forma, expressa a transferência do afeto humano para com seu próximo aos bens materiais, enfatizando que são pessoas incapazes de amar. Não no sentido sentimental ou moralizante, mas demonstrando a frieza nas relações humanas. (ADORNO, 1995a, p. 133).

O que Debord (1997) anunciou como sociedade do espetáculo é a revelação daquilo que, até então, permanecia obscuro perante a sociedade. A submissão social ao fetiche, ao capital, às imagens $e$, por consequência, ao espetáculo, trouxe um despertar da sociedade para um panorama até então submerso em seus próprios espetáculos sem a devida consciência 
de que "[,,,] o espetáculo na sociedade corresponde a uma fabricação concreta da alienação". (DEBORD, 1997, p. 24). Seus pressupostos deram estrutura para uma crítica da sociedade capitalista e o processo de abstração decorrente do modo de produção tanto individual como geral. Uma abstração que constitui "o modo de ser concreto" e que impede a consciência do processo, a consciência do fetiche do mundo, a consciência de uma sociedade na qual muitos apenas são espectadores e não tem sequer consciência de sua existência enquanto ser individual. (DEBORD, 1997, p. 23).

Toda a crítica argumentada por Debord (1997) deu respaldo para que se pudesse compreender a esfera de uma sociedade que sofreu inúmeras transformações, tanto no que se refere aos aspectos políticos, como econômicos, culturais e sociais. A importância do ter, sempre muito presente desde os primórdios do capitalismo, perde espaço agora para o "aparecer", haja vista que nada mais faz sentido numa esfera anônima. Os comportamentos engendrados ao simbolismo do espetáculo demonstram que nada na esfera individual possui significação se não "aparecer" ao coletivo, como uma simbiose entre aquilo que se vive e o que se configura como notável.

Nesse panorama no qual as coisas precisam possuir uma face espetacular para existirem, as necessidades e exigências continuam se reformulando diante da rapidez com que as imagens e mercadorias avançam em direção a um futuro que não se sabe mais a direção, já que a efervescência das relações agora se depara não só com as imagens, mas com as sensações e os vícios, como é o caso dos recentes aplicativos que envolvem uma participação real e emocional dos indivíduos.

Pensando nessas sensações e nos vícios, nos deparamos com uma Sociedade
Excitada, conceito trazido por Christoph Türcke, como uma ressignificação contemporânea do que a sociedade do espetáculo instaurou. Para Türcke (2010) o que se sobressai agora é a sensação. E a capacidade de provocar sensações se relaciona com aquilo que é percebido. Se antes o espetáculo estava relacionado ao aparecer, agora esse aparecer relaciona-se com o causar e sentir sensações. E o rumo vai na direção de que apenas o que causa uma sensação é percebido. (TÜRCKE, 2010, p. 20).

Türcke (2010) aponta as sensações como o que vem para ser agregado ao espetáculo e sua tese consiste no vício como algo decorrente dessa vasta produção de imagens sensacionais. Em outras palavras, as sensações presentes na sociedade atual se configuram como um vício, algo que tira a sobriedade das pessoas, deixando-as reféns dessas sensações $e$ buscando novas para manterem-nas excitadas. O autor utiliza-se das ideias de Marx, Freud e Nietzsche para desenvolver uma reflexão sobre o vício, a sociedade $e$ o consumo de imagens $e$ tecnologias. E concebe a excitação como uma forma de oposição à dominação em decorrência dos processos históricos e socioeconômicos. Uma forma de distração que vai ao encontro de uma fuga da realidade, no qual os produtos de alta tecnologias (high tech) são utilizados como uma forma de sair do estado de sobriedade para não haver consciência da situação concreta. Uma espécie de "ópio" capaz de manter o indivíduo distante da sociedade em que está inserido.

Santos (2012) ressalta que as ideias de Türcke (2010) apontam para um verdadeiro resgate dos impulsos violentos que marcam a separação do homem com a natureza $e$, nesse sentido, resgata e atualiza também a ideia do "entrelaçamento entre o mito $e$ o esclarecimento", discutidos por Adorno e 
Horkheimer na Dialética do Esclarecimento. Com isso ressalta-se uma busca incessante para "[...] descobrir por que a humanidade em vez de entrar num estado verdadeiramente humano, está se afundando numa nova espécie de barbárie". (ADORNO \& HORKHEIMER, 1985, p.11).

Nessa panorama, pensar a infância, é percebê-la em meio a tensão da era digital. As crianças encontram-se cercadas por telas que são tomadas como calmantes $e$, ao passo em que essas telas são utilizadas como "aliadas" no entretenimento das crianças, elas também estão presentes nas relações familiares, marcadas por diálogos e encontros virtuais. A exposição nas redes sociais, juntamente com a competição por likes, marcam esse panorama no qual a infância vivencia os conflitos entre a presença incontrolável (transformada em necessidade vitalícia) das tecnologias e um ambiente de relações sociais e familiares tecnologizadas.

Para compreender a concepção de infância que marcava os diferentes períodos históricos, Ariès (2006) realizou uma pesquisa baseada em imagens. Seu estudo possibilitou uma compreensão da infância em meio aos diversos contextos e representada de formas distintas, salientando aspectos simbólicos referentes à representação que se tinha da criança socialmente e no seio familiar. O autor, trouxe à tona uma história da humanidade marcada e compreendida por meio da categoria "infância", o que deu visibilidade a uma infância que, em muitos momentos, se manteve entrelaçada ao mundo adulto, sem contudo, um espaço peculiar para sua própria inserção social.

Inúmeros foram os autores que se debruçaram sobre os estudos de Ariès $e$ buscaram compreender a infância contemporânea. Neil Postman, ao trazer à tona o surgimento das tecnologias, aponta para um "desaparecimento da infância", tendo em vista o livre acesso aos mais diversos conteúdos e informações que a criança tem hoje em dia. Por outro lado, Sônia Kramer (2000), por ter uma experiência pessoal enquanto judia, se utilizou dos pesquisadores teóricos-críticos para analisar a criança $e$ a necessidade de educar contra a barbárie. Sobre as problemáticas que envolvem a criança atualmente $e$ as discussões que a colocam em questão, a autora aponta:

Mais recentemente, outras questões vêm inquietando os que atuam nesta área: trata-se de estudos críticos que denunciam o desaparecimento da infância. Perguntam de que infância falamos, já que a violência contra as crianças e entre elas se tornou uma constante, num contexto no qual as imagens de pobreza e mendicância de crianças, bem como o trabalho infantil, exemplificam uma situação em que o reino encantado da infância teria chegado ao final. Na era pósindustrial, na qual não haveria mais lugar para o "Era uma vez...", a idéia da infância, uma das invenções mais humanitárias da modernidade, estaria destruída; com a mídia, a televisão, a Internet, o acesso das crianças ao fruto proibido da informação adulta teria terminado por expulsá- las do jardim da infância (Postman, 1999). Reconheço a relevância destas indagações, mas não consigo evitar a pergunta: término da infância, desaparecimento da infância ou destruição da própria dimensão humana do homem? É a idéia de infância que entra em crise ou a crise é a do homem contemporâneo e de suas idéias em geral? Por outro lado, se levarmos em conta os diferentes contextos atuais - econômicos, sociais e culturais - veremos que esta miséria acompanha a história humana, desde sempre marcada por injustiça social $e$ desigualdade. (KRAMER, 2000, p. 3). 
Além da condição em que se encontram as crianças, hoje não somente a infância se torna objeto de estudo, como também o olhar das crianças para determinados elementos se transforma em uma forma subjetiva de compreender diferentes perspectivas, impregnadas das marcas da contemporaneidade. Türcke (2012) também trouxe considerações acerca da infância nos delírios da modernidade, ao traçar o perfil das crianças em meio ao emaranhado de redes $e$ telas. Para o alemão, as crianças vivem um estado de distração generalizada, a qual é capaz, ao mesmo tempo, de concentrar olhares e distrair mentes - ao que se deve ao fato dele nomear como "dispersão concentrada". Da mesma forma como Kramer (2000) questionou, Türcke (2012) também aponta para a destruição da dimensão humana em função do vício em que se encontra a sociedade hoje, que subordina uma pseudo-vivencia a um mundo forjado pelas câmeras.

$\mathrm{Na}$ imensidão de um paradigma tecnológico encontra-se uma infância tutelada pelas telas e imagens, que utilizamos como base nesse estudo - considerando a criança com até 12 anos incompletos, levando em consideração ainda o momento de descobertas, mas submersas em um contexto de telas e forte exposição imagética. A relação diária com esses aparatos permite uma identificação por parte das crianças que constroem um imaginário capaz de colocar as tecnologias na condição de autoridade tecnológica. Trata-se de desviar a autoridade acometida antes aos adultos, professores e demais referências na identidade infantil, para as máquinas. As telas que outrora serviam apenas como distração - e aqui não caberia a palavra diversão, haja vista a aproximação entre a diversão $e$ o trabalho em Adorno - hoje ocupam a posição de autoridade em meio às crianças que conferem suas informações e imagens como verdade suprema.
Os textos escritos pelas crianças $e$ coletados no desenvolvimento dessa pesquisa, demonstraram que todas as informações veiculadas pelos meios de pesquisa tecnológicos ganharam uma veracidade capaz de poder subjugar qualquer outra fonte que não se apoie nas telas. Além de ser o caminho mais rápido e prático para a realização de qualquer tipo de consulta, as tecnologias, associadas à internet, se transformaram no meio pelo qual as crianças conseguem realizar com independência qualquer busca que outrora precisava de um adulto para conhecer.

Agamben (2008), na obra Infância e História, faz um panorama sobre a dificuldade de realizar experiências na sociedade atual frente à tamanha "insignificância da vida contemporânea" e, para ele, "[...\} a esmagadora maioria da humanidade recusa-se hoje a experimentá-las: prefere que seja a máquina fotográfica a ter a experiência delas. (AGAMBEN, 2008, p. 23). A produção cultural fetichizada e o esvaziamento da experiência nos leva a uma infância também submersa na "banalidade do cotidiano".

Após a análise de imagens e produções infantis, coletadas em uma escola municipal de Ensino Fundamental, com crianças de faixa etária entre 8 e 11 anos, essa tensão tornou-se notória. Em paralelos às imagens que retratavam uma infância rodeada de telas $e$ aparelhos tecnológicos, com espaços virtuais $e$ jogos, encontrava-se uma percepção infantil melancólica com relação à forte presença das tecnologias em meio ao ambiente familiar. Para demonstrar essa posição, a análise foi realizada por meio de categorias retiradas dos próprios materiais infantis e subsidiada pelos estudos da Teoria Crítica, o que trouxe à tona a questão do vício, mencionado por parcela significativa das crianças em meio aos avanços da microeletrônica, além de temáticas como o 
consumo, a violência dos jogos, os aplicativos e a busca pela padronização de estilos e gostos.

O posicionamento das crianças com relação às tecnologias revelou-nos criticidade $e$, curiosamente, um pessimismo, ao indicar que os mesmos aparatos que possibilitavam uma aproximação virtual e uma conexão com o mundo, também distanciavam os momentos familiares. As crianças apontaram uma valorização, por parte dos pais, nas visitas em perfis de redes sociais em detrimento dos diálogos em família, além de uma importância maior às fotos postadas do que às vivências em si. Assim, o aspecto virtual sobressaia ao real e, portanto, sobrepunha-se à experiência.

Os dados demonstraram que $\mathrm{o}$ desenvolvimento das tecnologias torna cada vez mais estreita a relação entre o progresso, as técnicas $e$ a racionalidade instrumental. A reflexão trazida por Adorno e Horkheimer (1985) na Dialética do Esclarecimento, ganha vivacidade à medida que entendemos que "a superioridade do homem está no seu saber" porém esse saber utilizado para o desencantamento do mundo, apenas aproximou-o dos conflitos e, por meio de uma razão esclarecida, o trouxe à condição de refém de seu próprio conhecimento. "Resistir ao progresso, em sua condição fetichizada, é uma atitude crítica e educativa de não conformação - até quando perdurarem as "razões" que tornam o conhecimento técnico-científico possibilidades de expressão da irracionalidade. (COSTA, 2002, p. 190).

E é nessa tentativa de resistência que Adorno aponta a formação (bildung) no seu sentido mais amplo. Para ele, o processo formativo deve ter como meta a autonomia, a emancipação para lidar com o conhecimento, impedindo que o encantamento da sociedade na qual a indústria cultural se faz hegemônica, possa seduzir sem lampejos de pensamento autônomo. Salienta ainda uma preocupação com a educação na infância, resgatando as ideias de Freud sobre a formação da personalidade da criança. Essa preocupação é movida pelo medo de permitir que a criança tenha um desenvolvimento com resquícios de violência, seja física ou simbólica.

Adorno resgata elementos que instigam uma reflexão educacional, não para que se construa um projeto de educação, mas para que tenhamos ideia da urgência de impedir que a educação desvie de um caminho ético. Assim, lançamos mão de um debate sobre as tecnologias, pensando em seus paradoxos, na violência simbólica disseminada frente à dessensibilização dos indivíduos e na possibilidade de resistência, trazendo à tona uma reflexão entre a razão e os conflitos que cercam a natureza humana.

A crítica ao pensamento alienado culmina na crítica do próprio conhecimento científico que, ao passo em que se fortalece $e$ ultrapassa barreiras de tempo e espaço, perde de vista seus próprios meios no desejo insaciável pelo fim, uma dominação do mundo pelo homem. As tecnologias da comunicação surgiram em meio ao desejo de eliminar barreiras para o progresso e de estabelecer conexões que se aproximem da velocidade do próprio pensamento, inclusive por meio de associações de ideias, hipertextos e buscas imediatas. Entretanto, o perigo desse afunilamento entre os meios e o pensamento, consiste no que Adorno e Horkheimer (1985, p. 42) chamaram de "aparelhagem material $e$ aparelhagem intelectual" em uma tentativa falsa de reconciliar o pensamento solidificado frente ao domínio das máquinas. "Hoje, com a metamorfose que transformou o mundo em indústria, a perspectiva do universal, a realização social do pensamento, abriu-se tão 
amplamente que, por causa dela, o pensamento é negado pelos próprios dominadores como mera ideologia." (ADORNO E HORKHEIMER, 1985, p. 42).

\section{A atualidade da Dialética do} Esclarecimento se dá à medida que notamos hoje, com o crescente desenvolvimento tecnológico, a busca incessante por um conhecimento científico capaz de subjugar a própria história humana. A velocidade do progresso das técnicas $e$ as ramificações de especialistas que surgem cotidianamente salientam as necessidades de uma sociedade que clama por poder, pela dominação da natureza e do próprio homem enquanto parte desta. O desejo irrefreável por acúmulo de capital e mercadorias e pelo domínio do mercado culmina no próprio aprisionamento do homem em seus interesses. A necessidade de dominar a natureza também se encontra diretamente relacionada à subordinação aos seus interesses pessoais e calculistas, por meio de uma razão esclarecida inserida no sistema capitalista. "Na medida em que cresce a capacidade de eliminar duradouramente toda miséria, cresce também desmesuradamente a miséria enquanto antítese da potência e da impotência." (ADORNO E HORKHEIMER, 1985, p. 43).

Para tanto, Adorno propõe um pensamento que reflete sobre si, capaz de uma autorreflexão crítica. Somente refletindo sobre seu próprio pensamento e sua conduta é que se pode atingir uma autonomia de ideias capaz de tirar o indivíduo dessa condição de dominado por seu próprio conhecimento. $\mathrm{O}$ uso das tecnologias, enquanto parte do progresso que determina a sociedade, requer também esse exercício de autorreflexão a fim de não permitir que a pseudodemocratização de saberes se converta em saberes efetivamente reais.
Com base nesses pressupostos, ressaltamos a necessidade de que o processo de autorreflexão se socialize para que não resgatemos os elementos de uma época em que a criança vive à mercê de um mundo adulto, vendo na tecnologia a possibilidade de um crescimento imediato. É preciso revigorar o que Ariès (1981) chamou de "sentimento da infância", não deixando que as crianças apenas vivam à mercê de uma sociedade na qual não há espaço, nem tempo para suas peculiaridades, suas experiências e o desenvolvimento de um pensamento autônomo. Precisamos impedir o ofuscamento da infância frente ao brilho das telas e garantir que o lúdico não seja substituído pela técnica. Cabe lembrar que essa preocupação não se resume às crianças.

Adorno foi criticado por um olhar melancólico frente aos avanços das tecnologias $e$, hoje, não podemos desconsiderar que muitos estudos contemporâneos trazem as contribuições positivas das mídias e da cybercultura como um espaço de interação $e$ criatividade. Porém, a visão das crianças trouxe à tona um desânimo oriundo de uma utilização passiva dos meios virtuais que reacendem as preocupações dos estudiosos da Escola de Frankfurt. Para Adorno, a crítica da sociedade é também a crítica do conhecimento e, nesse sentido, na busca por caminhos éticos, a educação carece de constante reflexão... às tentativas de controle, à massificação, à estandardização, à agressividade e à falsa integração, a tudo isso é preciso se opor.

\section{REFERÊNCIAS}

ADORNO, Theodor W.; HORKHEIMER, Max. Dialética do Esclarecimento. Tradução: Guido Antonio de Almeida. Rio de Janeiro: Jorge Zahar Editora, 1985. 
ADORNO, Theodor. Educação e Emancipação. Tradução Wolfgang Leo Maar. Rio de Janeiro: Paz e Terra, 1995.

AGAMBEN, Giorgio. Infância e História: destruição da experiência e origem da história. Tradução de Henrique Burigo. Belo Horizonte: Editora UFMG, 2008.

ARIÈS, Philippe. História Social da criança e da

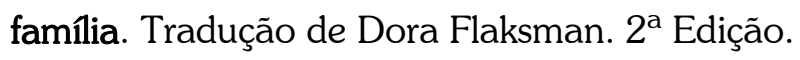
Rio de Janeiro: LTC, 2006.

BATISTA, Sueli Soares dos Santos. Teoria Crítica e Teorias Educacionais: uma análise do discurso sobre educação. In: Educação \& Sociedade, ano XXI, n. ${ }^{\circ}$ 73, 2000.

COSTA, Belarmino Cesar Guimarães da. Estética da Violência: jornalismo e produção de sentidos. Campinas, SP: Autores Associados; Piracicaba, SP: Editora Unimep, 2002.

DEBORD, Guy. A sociedade do espetáculo: comentários sobre a sociedade do espetáculo. Tradução de Estela dos Santos Abreu. Rio de Janeiro: Contraponto, 1997.

GALEANO, Eduardo. De pernas para o ar - a escola do mundo às avessas. Rio de Janeiro: LP\&M, 1999.

KRAMER, Sonia. Infância, cultura contemporânea e educação contra a barbárie. In: Seminário Internacional OMEP - InfânciaEducação Infantil: reflexões para o início do século. Brasil: 2000. KRAMER, Sonia; LEITE, Maria Isabel. (orgs.). Infância e Produção cultural. Campinas, SP: Papirus, 1998.

SANTOS. Patrícia da Silva. A "sociedade excitada": notas para a clínica. In: Trans/Form/Ação vol.35 no.1 Marília Jan./Apr. 2012. SCIELO. Disponível em Acesso em: 26 de novembro de 2014.
TÜRCKE, Christoph. Sociedade excitada: filosofia da sensação. Tradutores: Antônio A. S. Zuin (et al.). Campinas, São Paulo: Editora da Unicamp, 2010.

Hyperaktiv! Kritik der Aufmerksamkeitsdefizitkultur“ (Hiperativos! Crítica da cultura do déficit de atenção). Entrevista conduzida por Christiane Hoffmann (Frankfurter Allgemeine Zeitung). Tradução de José Pedro Antunes. 2012.

Recebido em: 09/03/2018

Aprovado em: 10/04/2018 